\title{
Kinetic Isotherm Studies of Azo Dyes by Metallic Oxide Nanoparticles Adsorbent
}

\author{
Madiha Batool ${ }^{1 *}$, Walid M Daoush ${ }^{2}$, Farwa Hashmi ${ }^{3}$, Nida Mehboob ${ }^{3}$ and Zahid Qureshi ${ }^{1}$ \\ ${ }^{1}$ Department of Chemistry, Government College University, Pakistan \\ ${ }^{2}$ Department of Production Technology, Faculty of Industrial Education, Helwan University, Egypt \\ ${ }^{3}$ Lahore college for Women University, Pakistan
}

Received: 眥 September 24, 2018; Published: 㘹 October 04, 2018

*Corresponding author: Madiha Batool, Department of chemistry GCU Lahore

\begin{abstract}
We reported the synthesis of $\mathrm{Cu}_{4} \mathrm{O}_{3}$ nanoparticles fabricated by Camellia Sinensis (green tea) leaves extract as reducing and stabilizing agent and studied the azo dyes removal efficiency. The formation of copper oxide nanoparticles was confirmed after change in solution of salt and plant extract from green to pale yellow. Subsequently, the above said nanoparticles were characterized by SEM, XRD, FTIR, and UV spectrophotometer for size and morphology. The average particle size of copper oxide nanoparticle was found to be $17.26 \mathrm{~nm}$ by XRD shrerrer equation, average grain diameter by SEM was calculated $8.5 \times 10-2 \mathrm{~mm}$ with spherical and oval shaped. UV spectroscopy range was between $200-400 \mathrm{~nm}$. These copper oxide nanoparticles were applied as azo dyes (Congo red and malachite green) degradation. Effect of reaction parameters were studied for optimum conditions. Kinetic models like Langmuir, Freundlich and elovich models were applied. Finally, concluded that these particles are effective degradation potential of azo dyes at about 70-75\% from aqueous solution.
\end{abstract}

Keywords: Green Tea; $\mathrm{Cu}_{4} \mathrm{O}_{3}$; Green synthesis; XRD; Congored; Malachite Green

\section{Background}

With elevating improvement in technology, the Scientific developments are approaching to new horizons [1]. Besides supplementary needs, the stipulation of industrial wastewater has increased swiftly, supervened in the huge amount of wastewater including azo dyes. Azo dyes are the foremost group of commercial pollutants [2]. Azo dyes are class of synthetic dyes with a complex aromatic structure and contain two adjacent nitrogen bond $(\mathrm{N}=\mathrm{N})$, that can accompany color to materials [3]. Furthermore, the aromatic structures of dyes form them sturdy and not- biodegrade [4]. Textile consume prodigious quantities of hazardous chemicals particularly in dyeing operations. This work is constructed on malachite green and congored azo dyes. The toxic Habit of the azo dyes can be elaborated by fact that upon decomposition it breaks up into hazardous products [5]. The MG and CR azo dyes toxic dye which has been removed from water samples through the physical, chemical and biological methods. Azo dyes are toxic, probably cause aesthetic problems and mutagenic and carcinogenic effects on human health, so must be degraded [6]. Therefore, the adsorption method by using copper oxide metal nanoparticles for wastewater treatment comprised with azo dyes. $\mathrm{Cu}_{4} \mathrm{O}_{3}$ nanoparticle were applied as an adsorbent for the degradation of MG and CR dyes and its kinetic and isotherm studies. Biogenic technology is regarded an emerging advancement of the current time which has been utilized to synthesize nanoparticles of a desired shape and size by using plant extract [7]. Consequently, the synthesized nanoparticles using innovative techniques which is used as cost-friendly reagent and less reactive. The work symbolizes application of conventional physical and also chemical methods for decolorization of azo dyes. physical method includes osmosis, filtration, adsorption and flocculation. the chemical method (oxidation, electrolysis) and biological method (microorganism, enzymes) are also applicable [8]. Green technology deals with the manipulation of matter at size typically b/w 1-100nm range. Nanoparticles having high surface to volume ratio responsible for enhanced properties [9]. Specific area is appropriate for adsorption property and other relevant properties such as dye removal [10].

Azo dye normally has aromatic structure and $\mathrm{N}=\mathrm{N}$ bond that's why they are hardly biodegradable $[11,12]$. These dyes have also mutagenic and carcinogenic effect. Normally, conventional methods have considerably less potential of degradation. Copper oxide 
nanoparticles have efficient power of dyes removal [12-17]. Most probably, copper oxide are low cost and novel adsorbent of azodyes. Copper oxide nanoparticle has efficiency of azo dyes removal from wastewater [12]. Malachite green dye $\left(\mathrm{C}_{23} \mathrm{H}_{25} \mathrm{~N}_{2}\right.$ with molar mass $364.911 \mathrm{~g} / \mathrm{mol}$ ) is organic in nature. Its lethal dose is $80 \mathrm{mg} / \mathrm{kg}$ the structure of malachite green dye is in Figure 1 below. Congo red an azo dye is sodium salt of $3,3^{\prime}$-bis structure. Congo red dye is water soluble, its solubility is enhanced in organic solvents. Its molecular formula is $\mathrm{C}_{32} \mathrm{H}_{22} \mathrm{~N}_{6} \mathrm{Na}_{2} \mathrm{O}_{6} \mathrm{~S}_{2}$ with molar mass of $696.665 \mathrm{~g} / \mathrm{mol}$ [1314]. The structure is given below Figure 2. The Camellia synesis is evergreen small tree. The Camellia synesis leaves act as capping and reducing agent during the synthesis of metal nanoparticle. There are certain properties of green tea extract such as antitumor, antioxidant, anticoagulant, antiviral, blood pressure and lowering activity [18-22] (Figure 3). Plant extract has some chemicals like phenols, acid, vitamins, responsible for reduction of metal [23]. Camellia synesis leaves have polyphenols, catechins (ECG), $\mathrm{OH}$ groups which cause copper metal reduction (Table 1). Copper oxide $\mathrm{Cu} 4 \mathrm{O} 3$ is known as paramelaconite material in tetragonal shape. Plants contain a wide range of secondary metabolites included phenolics help a vital role in the reduction of copper metal ions yielding nanoparticles [24]. Thus, ideally be used for the biosynthesis of nanoparticles. Copper oxide $\mathrm{Cu} 403$ is known as paramelaconite material in tetragonal shape. Copper nanoparticles synthesis by using green tea has Nano range particle size confirmed by characterization [25-28]. This is One-step processes in which no surfactants and other capping agents used.

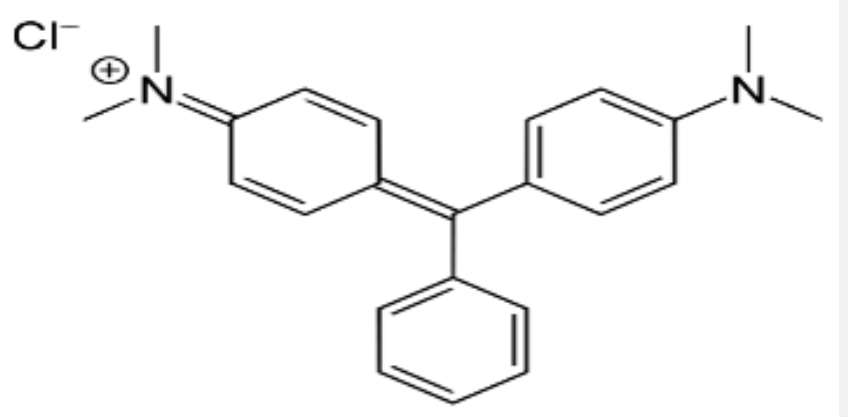

Figure 1: Malachite green dye.

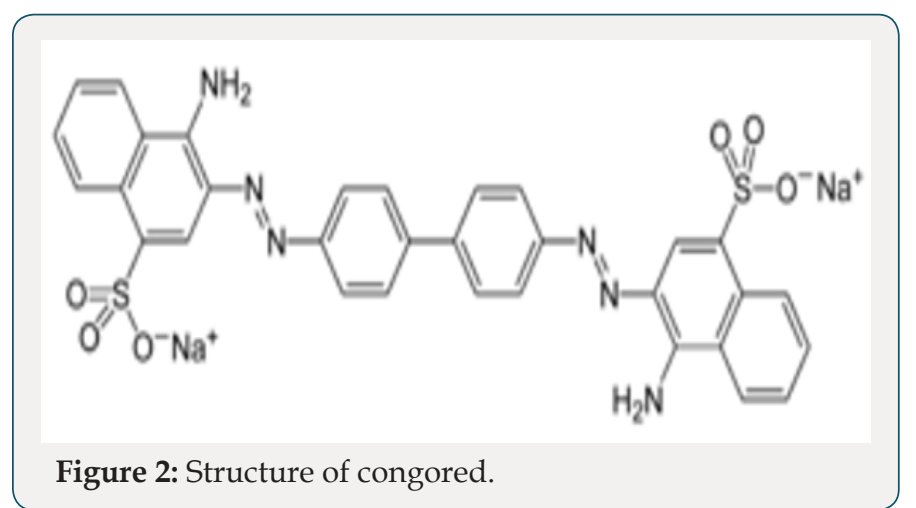

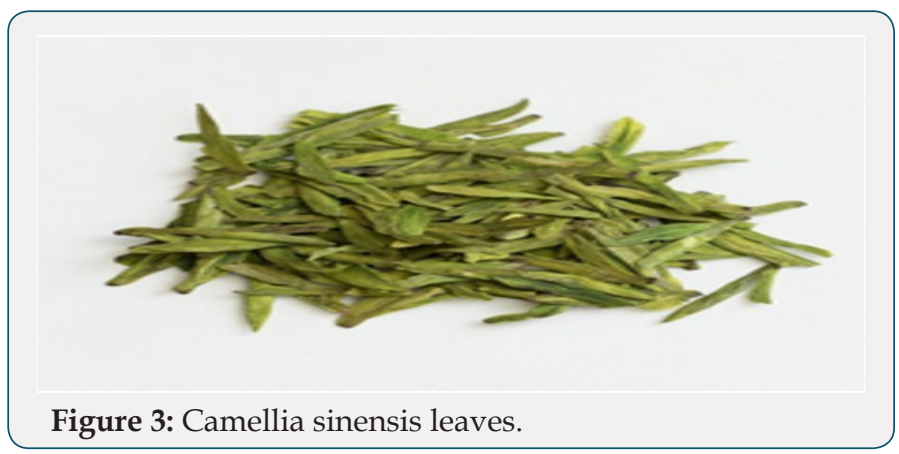

Table 1: Component of Camellia sinensis leaves [19].

\begin{tabular}{|c|c|}
\hline Components & \% age \\
\hline Phenolic compounds & 30 \\
\hline proteins & 15 \\
\hline Amino acid & 4 \\
\hline carbohydrates & 7 \\
\hline lipids & 7 \\
\hline Vitamin C, D & 10 \\
\hline
\end{tabular}

\section{Aims of Study}

The main aim of the study was

To extract copper nanoparticles using camellia sinensis leaves

a) To characterize the copper NPs

b) To study its potential to degrade azodyes

c) To find out the effect of different experimental parameters on \%degradation.

d) Kinetic study of adsorption of congored and malachite green dye

\section{Method}

\section{Material and Method}

The material used for the preparation of copper nanoparticles $\mathrm{Cu} 4 \mathrm{O} 3$ includes copper sulfate ( $\mathrm{CuSO}_{4} \cdot 5 \mathrm{H}_{2} \mathrm{O}$ from Sigma Aldrich) and camellia sinensis leaves (from botanical garden of institute) for the preparation of green tea extract. All chemicals used were of analytical grade and pure (Figure 4).

\section{Preparation of Green Tea Extract}

Green tea leaves of $30 \mathrm{~g}$ were taken and then washed with distilled water. further, the leaves were dried and then ground. The powder of green tea was used in the formation of extract [29]. The $100 \mathrm{ml}$ of deionized water was used. Later, the solution was boiled for 10 minutes and subsequently kept at low temperature after filtration. 

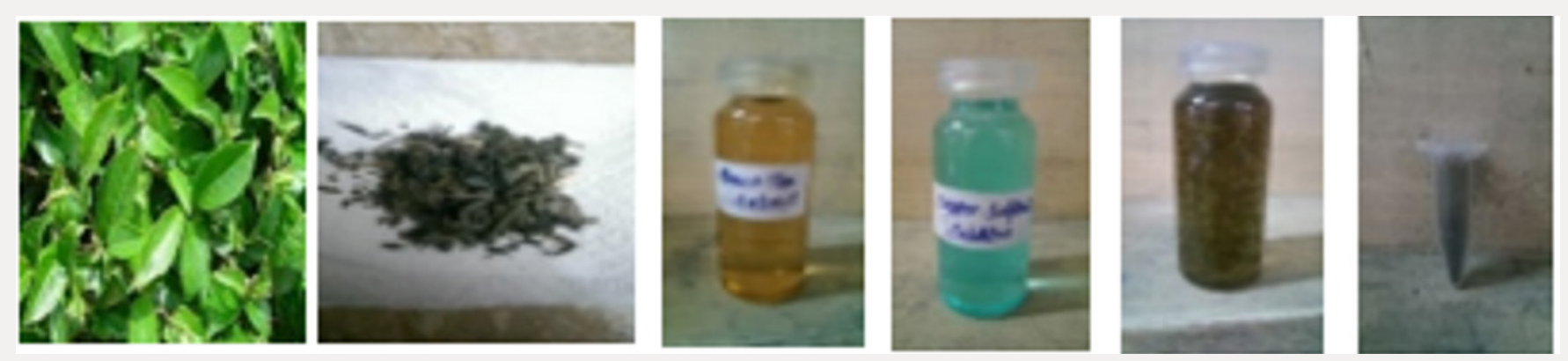

Figure 4: Steps of preparation of $\mathrm{Cu}_{4} \mathrm{O}_{3}$ nanoparticles.

\section{Preparation of $\mathrm{Cu}_{4} \mathrm{O}_{3}$ Nanoparticles}

A copper sulfate soln. of $50 \mathrm{ml}$ was added into $5 \mathrm{ml}$ of green tea extract. Magnetic stirrer was used for stirring. The color changed from green to pale yellow and finally dark brown confirmed the formation of nanoparticles. After the formation of nanoparticles, solution was centrifuged at the speed of 1000 rpm for 20 mins. After the removal of supernatant copper oxide nanoparticles were dried and washed with ethanol. At the end calcination was performed at 500 degree for one hour and resultantly black colored particles were collected for characterization [27-29].

\section{Results}

\section{Characterization of $\mathrm{Cu}_{4} \mathrm{O}_{3}$ Nanoparticles}

UV spectrophotometer, X-ray diffractometer (XRD), Fourier transform infrared spectrophotometer (FTIR) and Scanning electron microscope (SEM) were used in order to characterize the size, shape, chemical and structural composition of $\mathrm{Cu}_{4} \mathrm{O}_{3}$ nanoparticles [30]. During the study, the green color soln. transformed into dark brown which confirm the formation of copper oxide nanoparticles.

\section{X-Ray Diffraction Studies}

The X-ray diffraction pattern of copper oxide nanoparticles were examined by x-ray diffractometer. To determine the intensity of copper oxide nanoparticles, the powder was added in the XRD cubes for analysis. The resultant pattern of the copper oxide nanoparticles was matched with JCPDS card number (033-0480), the peaks at $2 \theta$ intensity 28.09, 30.61, 36.14 and 44.14 and have 112, 103, 202 and 213 patterns respectively. However, average crystal size calculated by the Scherrer equation keeping lemda at 0.154 and FWHM value calculated 0.5 found was $17.2 \mathrm{~nm}$. The shapes of the particles of $\mathrm{Cu}_{4} \mathrm{O}_{3}$ nanoparticles in XRD was tetragonal [31-33].

\section{Name and Formula}

Reference code: 00-033-0480

Mineral name: Paramelaconite

Compound name: Copper Oxide

Empirical formula:
Chemical formula:

$$
\mathrm{Cu}_{4} \mathrm{O}_{3}
$$

\section{Crystallographic Parameters}

Crystal system: Tetragonal

Space group: I41/amd

Space group number: 141

a $(\AA): 5.837$

b $(\AA)$ :

c (̊̊): 9.932

Alpha $\left(^{\circ}\right): 90.00$

Beta $\left({ }^{\circ}\right): \quad 90.00$

Gamma $\left({ }^{\circ}\right): 90.00$

Calculated density $\left(\mathrm{g} / \mathrm{cm}^{-3}\right)$ :

Measured density $\left(\mathrm{g} / \mathrm{cm}^{-3}\right)$ :

Volume of cell $\left(10^{\wedge} 6 \mathrm{pm}^{-3}\right)$ :

\section{Peak List}

No. h k l d [A] 2Theta[deg] I [\%]

11015.0320017 .6112 .0

21123.1740028 .091100 .0

32002.9180030 .61338 .0

40042.4830036 .1467 .0

52202.0640043 .8277 .0

62132.0500044 .1425 .0

72041.8912048 .07216 .0

81051.8805048 .36310 .0

93121.7302052 .87321 .0

102241.5871058 .07110 .0 
111161.5364060 .1817 .0

124001.4592063 .7263 .0

133321.3258071 .0433 .0

144201.3052072 .3393 .0

154041.2581075 .5082 .0

163161.2324077 .3705 .0

174241.1553083 .6343 .0

182081.1424084 .7972 .0

195121.1155087 .3462 .0

(Figure 5)

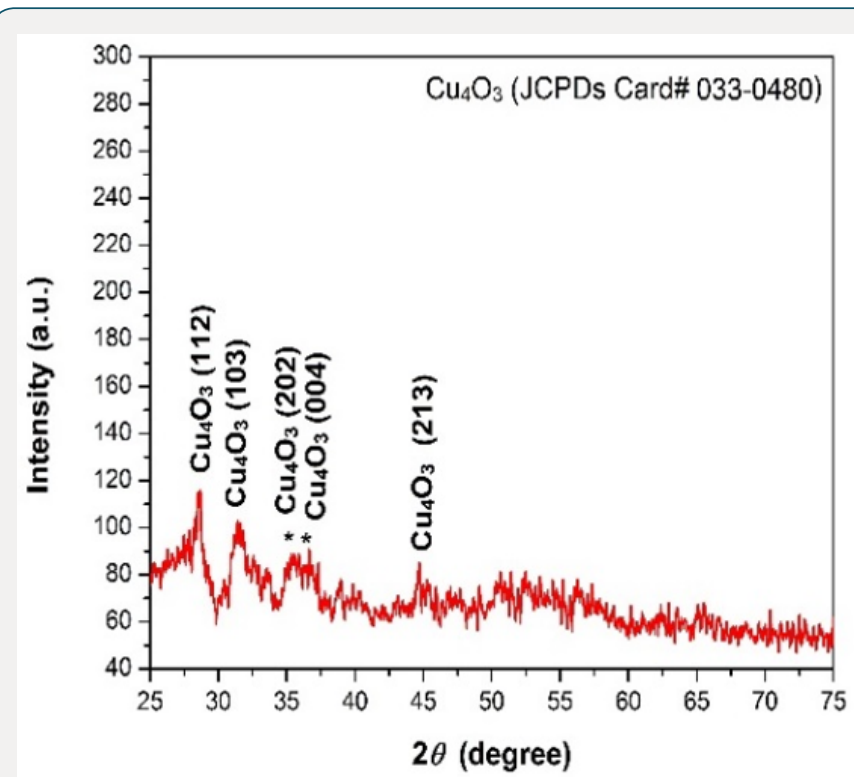

Figure 5: XRD pattern of copper oxide $\left(\mathrm{Cu}_{4} \mathrm{O}_{3}\right)$ nanoparticles.

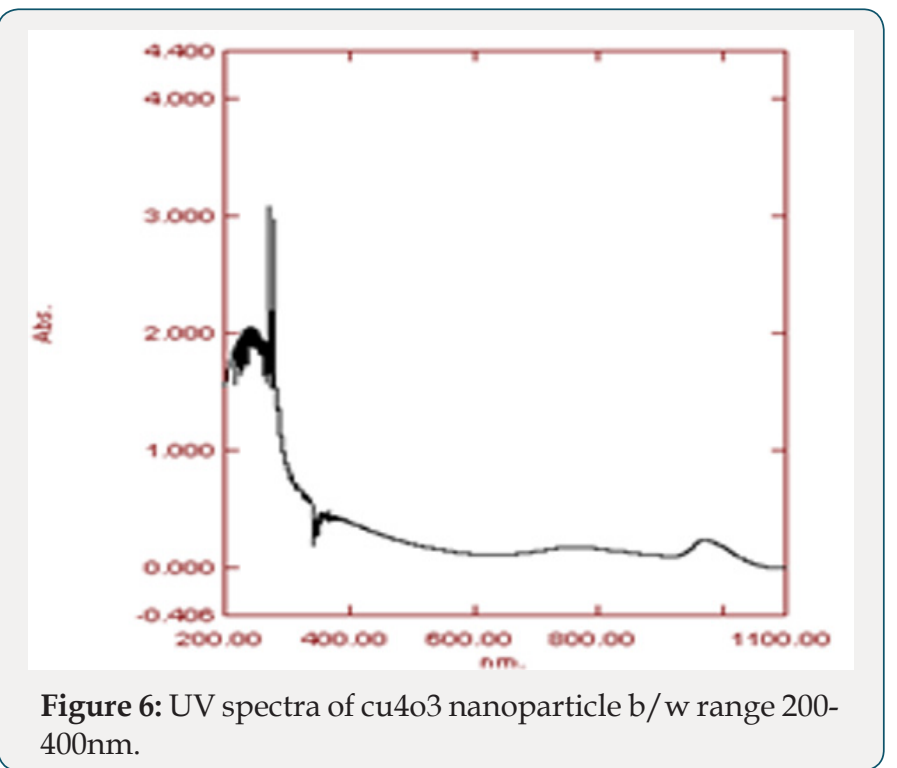

Ultraviolet Spectroscopy: The range at which copper oxide nanoparticles appeared was 200-400nm. The maximum absorption peak was confirmed at $280 \mathrm{~nm}$ which confirmed the copper oxide nanoparticles (Figure 6).

FTIR Analysis: In the current study, FTIR spectrum was examined to determine the copper nanoparticles functional group peaks. The overall peak was observed in ranged from 400 to $4000 \mathrm{~cm}^{-1}$. The spectrum at peak $3310.7 \mathrm{~cm}$ and $1611.2 \mathrm{~cm}$ revealing the (Figure 7) presence of alcoholic group. The bands at $3310.7 \mathrm{~cm}^{-}$ 1 , and $2850 \mathrm{~cm}^{-1}$ another functional group present are listed in table below (Table 2).

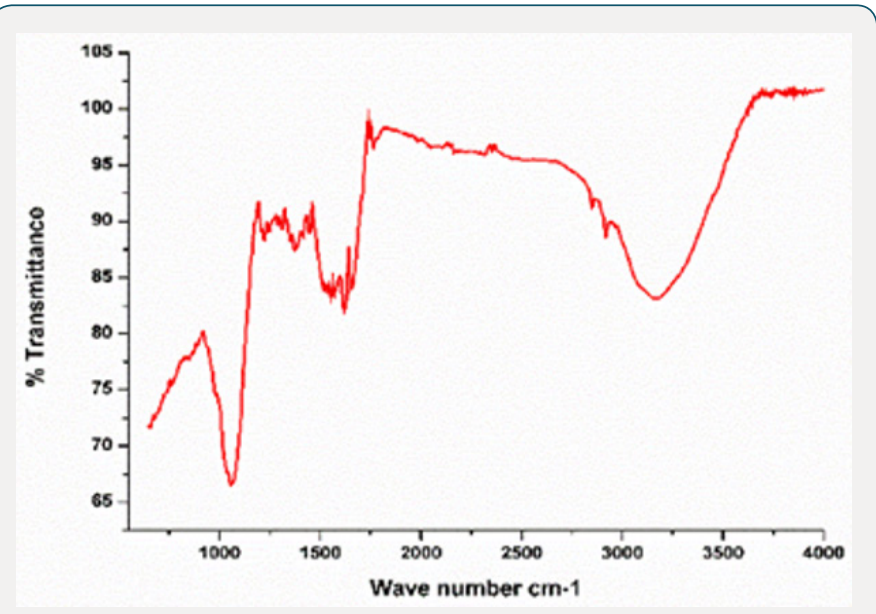

Figure 7: FTIR spectra of $\mathrm{Cu}_{4} \mathrm{O}_{3}$ nanoparticles.

Table 2: Functional group in FTIR spectra.

\begin{tabular}{|c|c|c|}
\hline Groups & $\begin{array}{c}\text { Stretching and } \\
\text { bending }\end{array}$ & Range \\
\hline O-H group & Stretching & $3310.7 \mathrm{~cm}^{-1}$ \\
\hline C-H group & stretching & $2850 \mathrm{~cm}^{-1}$ \\
\hline C=C group & Aromatic bending & $1611.2 \mathrm{~cm}^{-1}$ \\
\hline C-H group & & $1344.2 \mathrm{~cm}^{-1}$ \\
\hline Cu-O & stretching & $1100 \mathrm{~cm}^{-1}$ \\
\hline
\end{tabular}

SEM Analysis: The average particle size of copper nanoparticle was analyzed by SEM model (JSM-6480). The range of grain of copper oxide nanoparticle was calculated about $8.5 \times 10-2 \mathrm{~mm}$ by SEM micrograph. The prepared copper oxide nanoparticles were well dispersed. It was observed that particles were smooth with a tetragonal shape (Figure 8).

\section{Removal of Malachite Green and Congo Red Azo Dye by $\mathrm{Cu}_{4} \mathbf{o}_{3}$ Nanoparticles}

Preparation of Standard Solution: In 1-liter distilled water, the dye was dissolved to prepare $1000 \mathrm{ppm}$ solution of malachite green and Congo red. From stock solution different concentrations of dyes were prepared. After dilution from 1000ppm solution to 
$100 \mathrm{ppm}$ solution was prepared. From that 150, 200, 250-ppm solution were prepared. Efficiency of Color removal was calculated by percentage degradation formula
$\%$ decolorization of dye $=\mathrm{A}-\mathrm{B} / \mathrm{A} \times 100$.

Where A and B are absorbance of dye solution without nanoparticles and with particles respectively.

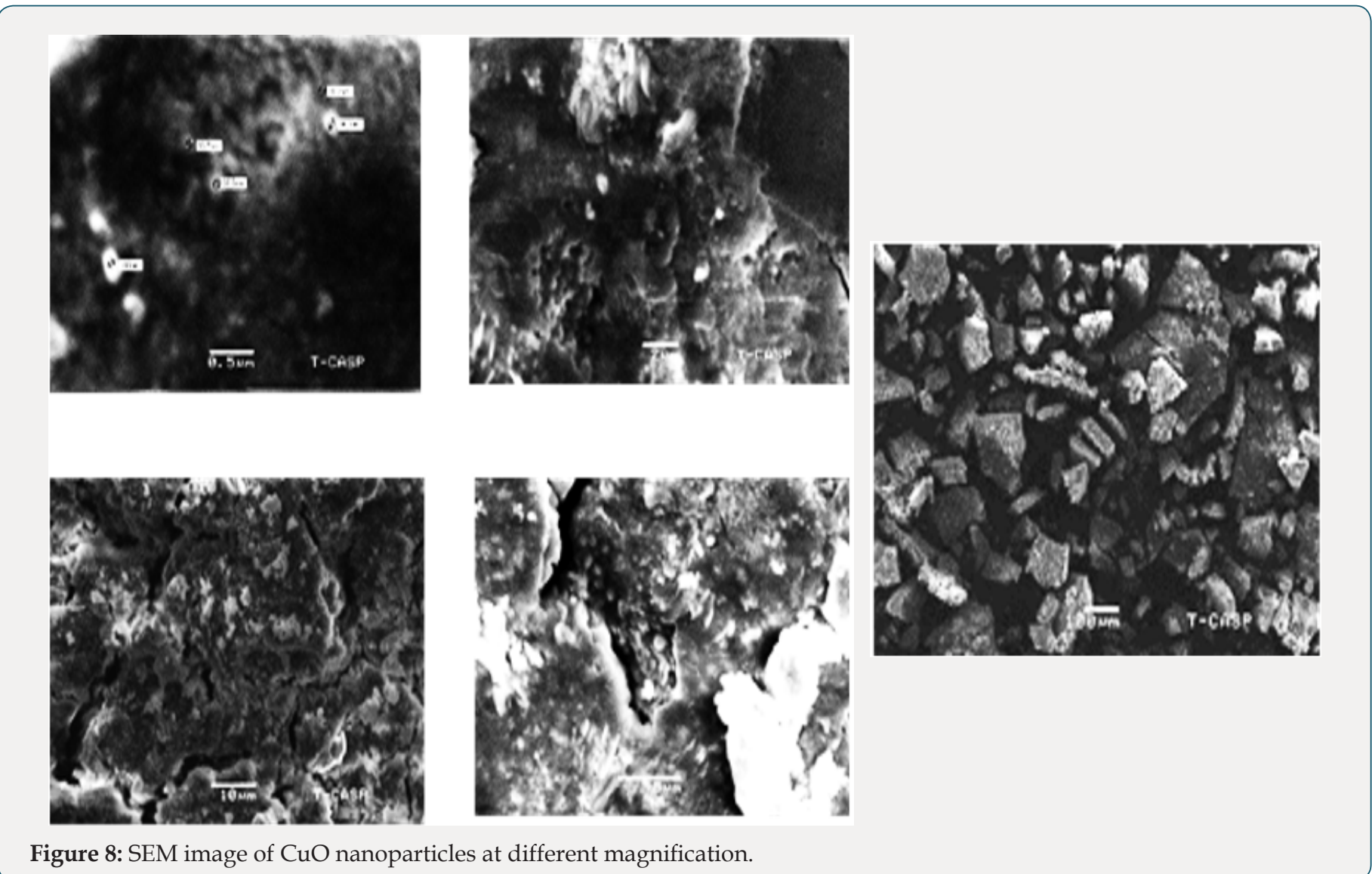

\section{Mechanism of Azodye Degradation}

50 microliter of the hydrogen peroxide $\mathrm{H}_{2} \mathrm{O}_{2}$ was added as the oxidizing agent to yield hydroxyl radical. Catalytic activity process mainly depends on the formation of superoxide anion radical and hydroxyl radical. The concentration of CR and MG dyes in aqueous solutions were measured by UV-vis spectrophotometer. A reducing agent $\mathrm{H}_{2} \mathrm{O}_{2}$ was added with adsorbent to check the adsorption capacity.

\section{Effect of Experimental Parameters On \% Degradation of Dye Removal}
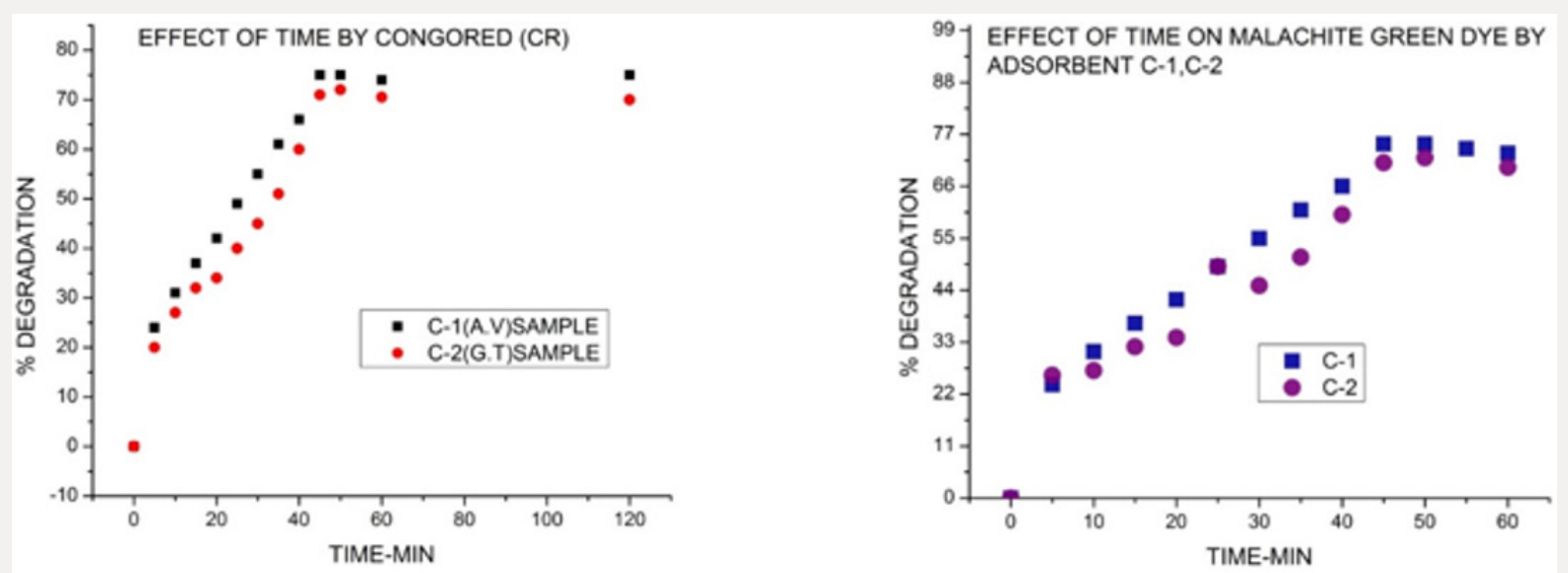

Figure 9: Effect of time by copper oxide nanoparticles samples C-1, C-2(Green tea mediated) on malachite green dye and Congo red dye calculated by ultraviolet spectrophotometer DB-20. 
Time effect: Effect of time on percentage degradation of azo dyes was also studied by UV spectrophotometer. The samples of copper oxide NPs synthesized by green tea C-1, C-2(GT) were calculated. The time required for removal of above said dye was between (40-45 min) and percentage removal was observed for all samples between $70-75 \%$. The result of graphs clearly shows the time effect on color degradation of azo dye malachite green-MG and acid red 28-CR by using adsorbent copper oxides nanoparticles. The experimental conditions during experiment were kept constant just like temperature 308 kelvin and initial concentration of adsorbent was within ranges from 20-250mg/l. Samples C-1, C-2 are samples codes synthesized by camellia sinensis leaves extract at different temperatures. In figure below $\mathrm{C}-1$ sample is dye + adsorbent $+\mathrm{H}_{2} \mathrm{O}_{2}$ and $\mathrm{C}-2$ sample without reducing agent. It was concluded from graphs \%degradation enhanced in presence of reducing agents.
Figure 9 Effect of time by copper oxide nanoparticles samples C-1, $\mathrm{C}$-2(Green tea mediated) on malachite green dye and Congo red dye calculated by ultraviolet spectrophotometer DB-20.

Ph Effect: Effect of PH on removal of congored and malachite green azodyes by UV spectrophotometer was studied. The \% degradation of azodyes was experimentally performed at $\mathrm{PH}$ range (2-14). The maximum PH observed for C-1, C-2 copper oxide NPs samples synthesized by Green tea was 3 for maximum removal of dyes. Below and above this PH degradation was constant. This conclude that $\mathrm{PH}$ effect on dye removal efficiency. The graphical representation of effect of PH is shown below Figure10. Effect of PH by copper oxide nanoparticles sample C-1, C-2(synthesized by green tea) on malachite green dye and congored by ultraviolet spectrophotometer DB-20.
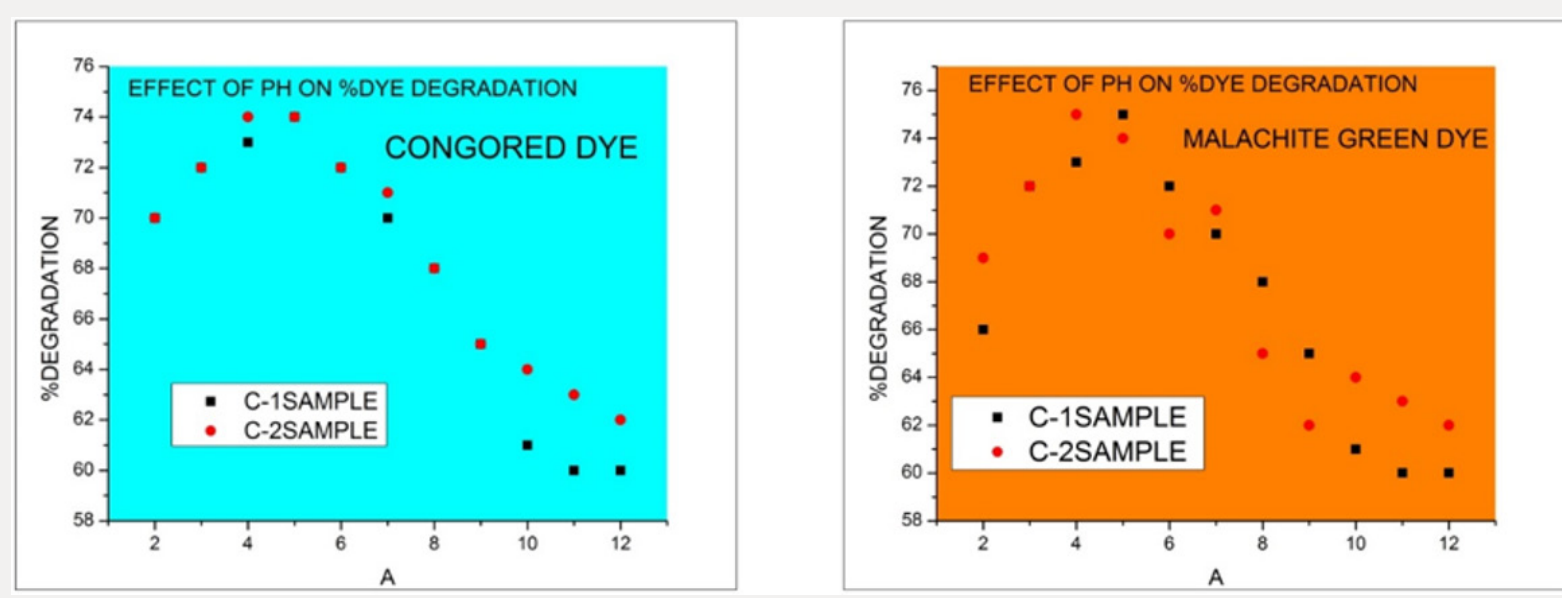

Figure 10: Effect of PH by copper oxide nanoparticles sample C-1, C-2(synthesized by green tea) on malachite green dye and congored by ultraviolet spectrophotometer DB-20.

Temperature Effect: The temperature effects on percentage degradation effectively. The observed results indicate that after increasing temperature from 35-80 degree the percentage removal potential of copper oxides NPs samples C-1, C-2 (green synthesized by Green tea) increases. The graphical representation of temperature effect of is shown below in Figure 11. Effect of temperature by copper oxide nanoparticles samples C-1, C-2 (synthesized by green tea) on malachite green dye and congored dye calculated by ultraviolet spectrophotometer DB-20.
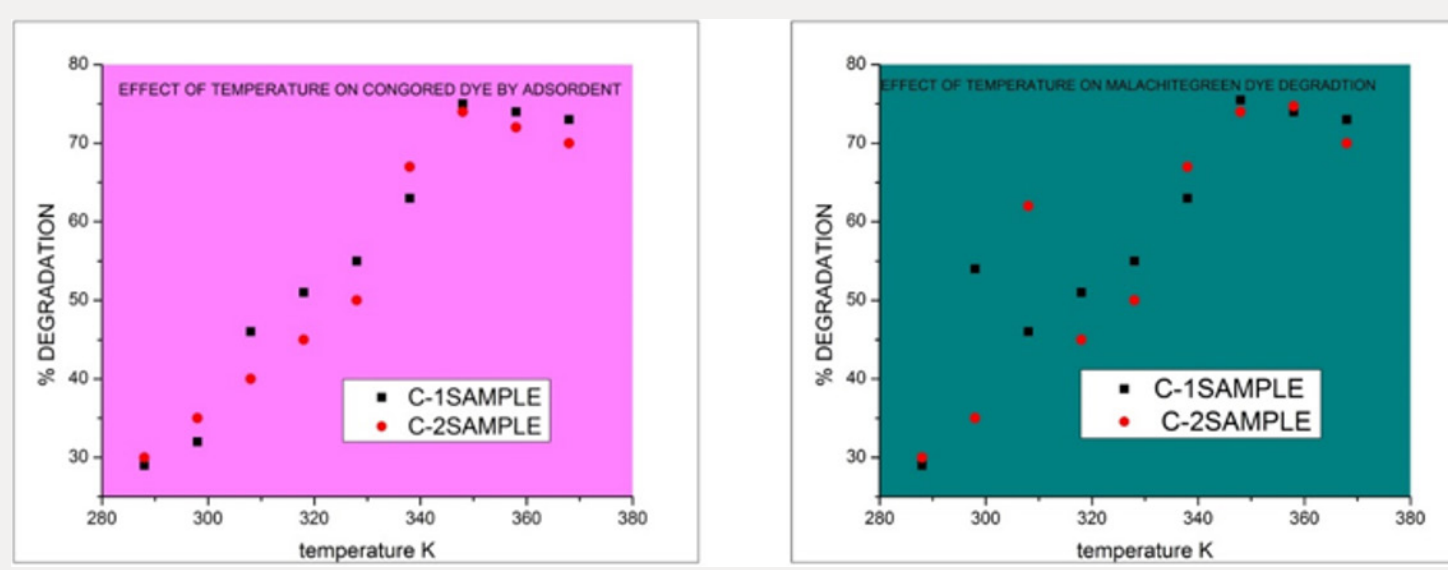

Figure 11: Effect of temperature by copper oxide nanoparticles samples C-1, C-2 (synthesized by green tea) on malachite green dye and congored dye calculated by ultraviolet spectrophotometer DB-20. 
Adsorption Kinetics Studies: The kinetics of azo dye adsorption was carried under selecting optimum operating conditions. The kinetic parameters are helpful for the estimation of adsorption rate. A solution prepared by dissolving $20 \mathrm{mg}$ of adsorbent in $50 \mathrm{ml}$ of $10 \mathrm{ppm}$ dyes and continuously stirred.

Adsorption Kinetic Studies of Copper Oxide NPs: The pseudo-second-order model was found to explain the adsorption kinetics most effectively. The results indicated a significant potential of nanoparticles as an adsorbent for azo dye removal. The straight line shows that nanoparticles follow pseudo-second-order kinetics rather than first orde.

$$
\frac{\mathrm{d} q_{t}}{\mathrm{~d} t}=k_{1}\left(q_{e}-q_{t}\right)
$$

The graphical representation shows that copper oxide nanoparticles show pseudo-second-order kinetics (Figures 12 \& 13).

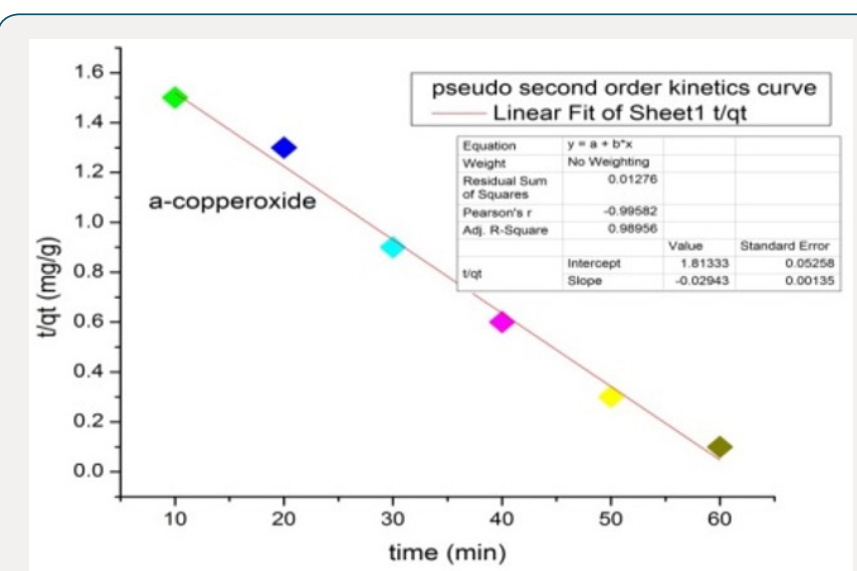

Figure 12: Pseudo-second-order kinetics of $\mathrm{cu}_{4} \mathrm{O}_{3} \mathrm{NPs}$ by malachite green dye.

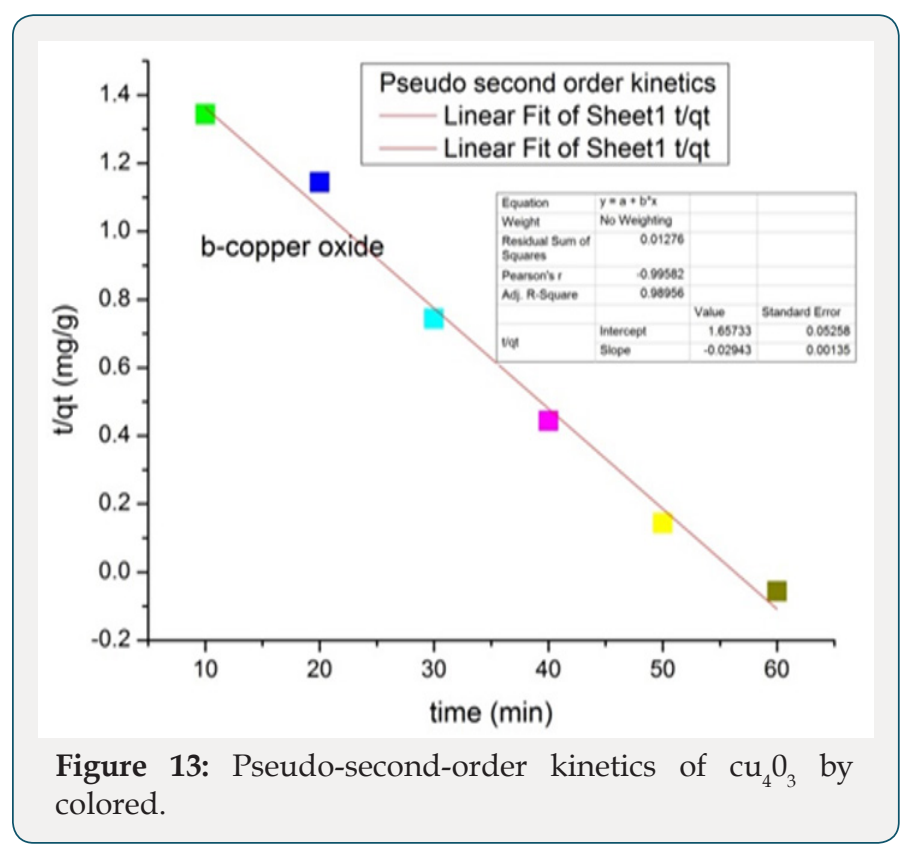

\section{Adsorption Reaction Isotherm Models}

Langmuir Isotherm Model: The Langmuir isotherm is applicable for adsorption of a solute as monolayer adsorption on a surface having few numbers of identical sites. Langmuir isotherm model provide energies of adsorption onto the plain. That's why, the Langmuir isotherm model is selected for adsorption capacity relating to monolayer surface of adsorbent. Adsorption process fits the Langmuir and pseudo-second-order models. Langmuir isotherm or single crystal surfaces describes well adsorption at low medium coverage, adsorption into multilayer is ruled out. Parameters of different models studied in this research are listed below in Table 3.

Table 3: Parameters of adsorption models CR congored dye, MG malachite green dye at 35C0.

\begin{tabular}{|c|c|c|c|}
\hline model & parameter & MG & CR \\
\hline Langmuir & qe & 18.6 & 16.8 \\
\hline & KL & 0.65 & 0.6 \\
\hline & $\mathrm{R} 2$ & 0.991 & 0.998 \\
\hline Freundlich & $\mathrm{n}$ & 0.59 & 0.51 \\
\hline & $\mathrm{KF}$ & 1.4 & 1.98 \\
\hline & $\mathrm{R} 2$ & 0.905 & 0.903 \\
\hline Elovich & $\alpha$ & 10.3 & 9.98 \\
\hline & $\beta$ & 14.2 & 15.3 \\
\hline & $\mathrm{k}$ & 2.05 & 2.09 \\
\hline & $\mathrm{R} 2$ & 0.956 & 0.951 \\
\hline Pseudo-second -order(linear) & $\mathrm{qe}$ & 16.9 & 20.2 \\
\hline & $\mathrm{K} 2$ & 0.068 & 0.069 \\
\hline & $\mathrm{R} 2$ & 0.989 & 0.98 \\
\hline & $\mathrm{t} / \mathrm{qt}$. & & \\
\hline & & 1.81 & 1.65 \\
\hline & $\mathrm{SE}$ & 0.003 & 0.005 \\
\hline & $\mathrm{C} 0$ & 20 & 20 \\
\hline
\end{tabular}

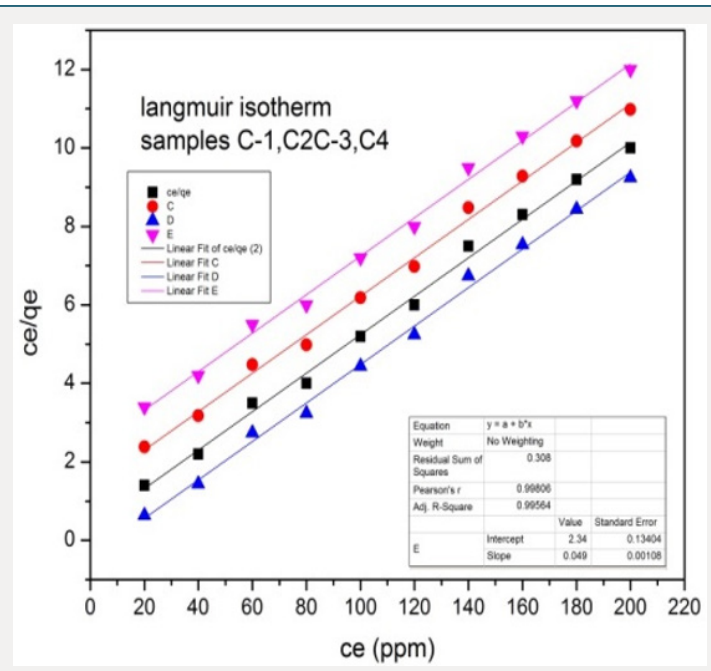

Figure 14: Langmuir model of C-1, C-2 samples for congored and malachite green dye. 
The Langmuir equation is listed below

$\mathrm{Ce} / \mathrm{qe}=1 / \mathrm{KLqm}+(1 / \mathrm{qm})$ Ce (Figure 14$)$.

In the equation $\mathrm{qm}$ is adsorption capacity in unit $\mathrm{mg} / \mathrm{g}$. Langmuir isotherm constant is KL. langmuir constant provide the binding affinity $\mathrm{b} / \mathrm{w}$ adsorbent and dyes. The values of isotherm qm and constant KL can be calculated by plotting a graph between Ce /qe and Ce. The characteristics of a Langmuir isotherm can be examined in terms of equilibrium parameter. KL was calculated by formula

$$
\mathrm{RL}=1 / 1+\mathrm{KLCe}
$$

Freundlich Isotherm Model: The Freundlich isotherm model is suitable for the adsorption of dye on the adsorbent. Freundlich equation is stated below

In qe $=\mathrm{Kf} \mathrm{qm}+1 / \mathrm{n}$ InCe

qe is the amount used of azo dye in unit of $\mathrm{mg} / \mathrm{g}$, Ce is the equilibrium concentration of the azo dye and $\mathrm{Kf}$ and $\mathrm{n}$ are constants factors affecting the capacity of adsorption and adsorption speed. The graph between lnqe versus In Ce shows linearity. The adsorption reaction isotherms are fitted to models by linear square method. The result shows in this study that Langmuir model fit better than the Freundlich model. The adsorption activity of copper oxide nanoparticle samples prepared by green source were observed against the degradation of malachite green and congored azodyes (Figure15).

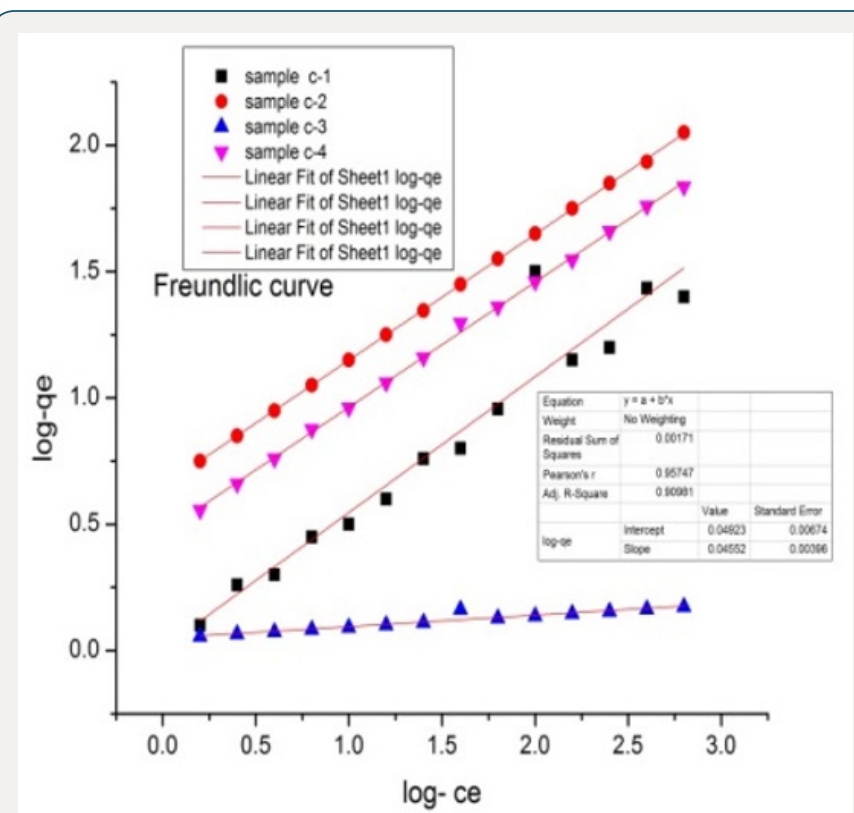

Figure 15: Freundlich model of samples C-1.C-2 for congored and malachite green dye.

Elovich Adsorption Model; Elovich model is used in adsorption reaction kinetics. It deals with mechanism of reaction take place.
The pseudo-second-order reaction differs with elovich model in type of constants. Elovich model used to study rate constant and pseudo-second-order half-life time and initial rate of reaction is calculated. In Elovich model logarithmic mathematic function are applied. This model shows chemisorption.

$$
q t=\operatorname{In}(\alpha \cdot \beta)+\operatorname{Int}
$$

(Figure 16)

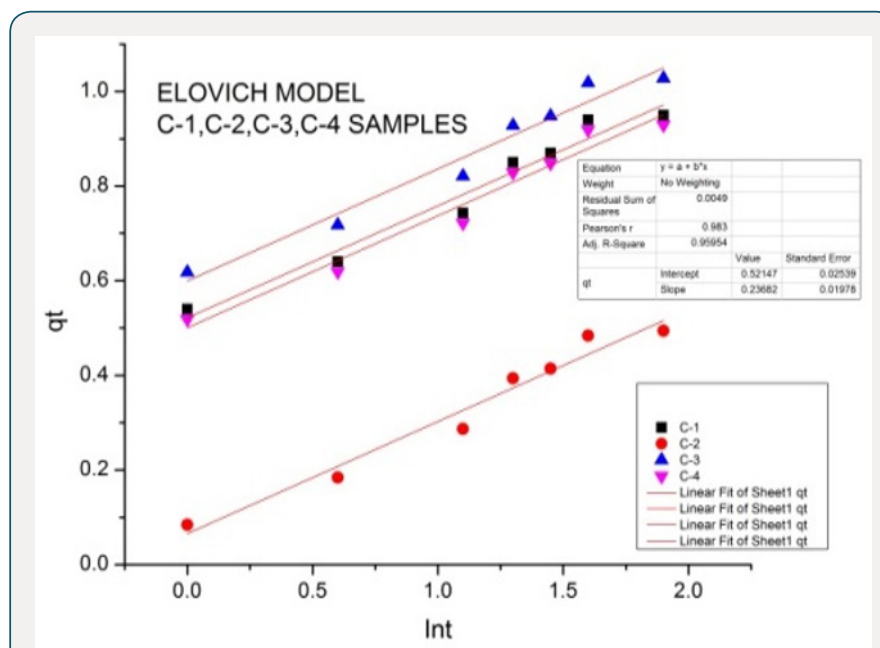

Figure 16: Elovich model of C-1, C-2 samples by congored and malachite green dye.

\section{Discussion}

In present we reported an eco-friendly and cost-efficient preparation of copper oxide nanoparticles by leaf extract of camellia sinensis. the characterization of particles were performed by SEM, UV, XRD, FTIR analysis. UV spectroscopy peak was observed at $280 \mathrm{~nm}$ and a broadband observed which confirmed nanoparticles existence. The particle size was calculated by Scherrer equation was $17.26 \mathrm{~nm}$. The SEM results confirmed tetragonal shape of cu403 particles with grain average diameter $8.5 \times 10-2 \mathrm{~nm}$, and FTIR spectra indicated the peaks of $\mathrm{OH}, \mathrm{C}=\mathrm{C}, \mathrm{C}-\mathrm{H}$ functional groups, which is due to thin coating of extract on nanoparticles. The calculated surface area of nanoparticles was $65 \mathrm{~m}^{2} / \mathrm{g}$. The $\%$ degradation of azo dyes malachite green and congored range were $\mathrm{b} / \mathrm{w} 70-75 \%$ at maximum $0.2 \mathrm{~g} / \mathrm{l}$ and $20 \mathrm{mg} / \mathrm{l}$ dosage of adsorbent and dye. The optimum time was b/w 30-40mint, PH 3-4, temperature 70-80 Co for maximum degradation. The effect of different experimental parameters was studied on percentage degradation of dyes. The azo dyes congored and malachite green dyes adsorption isotherm models were studied. The reaction kinetics followed pseudo second order for both dyes rather than first order. The Langmuir model fit better with linearity rather than Freundlich, which confirmed by graph having r2 0.98,0.99and0.95 values for models. The elovich model also linear fit. In conclusion, copper oxide nanoparticles keep excellent azo dyes degradation potential. 


\section{Conclusion}

In present we reported an eco-friendly and cost-efficient preparation of copper oxide nanoparticles by leaf extract of camellia Sinensis. According to kinetic study it proved that $\mathrm{Cu} 403$ NPs keep excellent adsorption capability for MG and CR azo dyes.

\section{Authors Contribution}

All data analysis experimental and graphical. Author conduct and drafted research.

\section{Acknowledgment}

Thanks to GCU CASP department for providing SEM, XRD, FTIR facility.

\section{References}

1. Aksu Z (2001) Biosorption of reactive dyes by dried activated sludge: Equilibrium and kinetic modeling. Biochem. Eng J 7(1): 79-84.

2. Aksu Z (2005) Application of biosorption for the removal of organic pollutants: A review. Process Biochem 40(3-4): 997-1026.

3. Chang MW, Chung CC, Chern JM, Chen TS (2010) Dye decomposition kinetics by UV/H2O2: Initial rate analysis by effective kinetic modeling methodology. Chem Eng Sci 65(1): 135-140.

4. Irama M, Guo C, Guan Y, Ishfaq A, Li H (2010) Adsorption and magnetic removal of neutral red dye from aqueous solution using $\mathrm{Fe}_{3} \mathrm{O}_{4}$ hollow nanospheres. Journal of Hazardous Materials 81(1-3): 1039-1050.

5. Chung KT, Fulk GE, Egan M (2010) Reduction of azo dyes in intestinal anaerobes. Appl Environ Microbiol 35(3): 558-562.

6. Ruan X, Huang S, Chen H, Qian G (2013) Sorption of aqueous organic contaminants onto dodecyl sulfate intercalated magnesium iron layered double hydroxide. Appl Clay Sci 72: 96-103.

7. Asghar MA, Zahir E, Shahid SM, Khan MN, Asghar MA, et al. (2018) Iron, copper and silver nanoparticles: Green synthesis using green and black tea leaves extracts and evaluation of antibacterial, antifungal and aflatoxin B 1 adsorption activity. LWT 90: 98-107.

8. Saranya S, Eswari A, Gayathri E, Eswari S, Vijayarani K (2017) Green Synthesis of Metallic Nanoparticles using Aqueous Plant Extract and their Antibacterial Activity. Int J Curr Microbiol App Sci 6(6): 1834-1845.

9. Jeevan JM, Umesh KG (2017) Green synthesis of copper nanoparticles using tea leaf extract. International Journal of Engineering Science Research and Technology 6(7): 307-311.

10. Suárez-Cerda J, Espinoza-Gómez H, Alonso-Núñez G, Rivero IA, GochiPonce $Y$, et al. (2017) A green synthesis of copper nanoparticles using native cyclodextrins as stabilizing agents. Journal of Saudi Chemical Society 21(3): 341-348.

11. Gottimukkala KSV (2017) Green synthesis of iron nanoparticles using green tea leaves extract. J Nanomed Brother Discov 7: 151.

12. Altikatoglu M, Attar A, Eric F, Cristache CM, Isildak I (2017) Green synthesis of copper oxide nanoparticles using Ocimum Basilicum extract and their antibacterial activity. Fresenius Environmental Bulletin 26(12A): 217-222

13. Ijaz F, Shahid S, Khan SA, Ahmad W, Zaman S (2017) Green synthesis of copper oxide nanoparticles using Abutilon Indicum leaf extract: Antimicrobial, antioxidant and photocatalytic dye degradation activities. Tropical Journal of Pharmaceutical Research 16(4): 743-753.

14. Shi LB, Tang PF, Zhang W, Zhao YP, Zhang LC, Zhang H (2017) Green synthesis of $\mathrm{CuO}$ nanoparticles using Cassia auriculata leaf extract and in vitro evaluation of their biocompatibility with rheumatoid arthritis macrophages (RAW 264.7). Tropical Journal of Pharmaceutical Research 16(1): 185-192.

15. Chung IM, Abdul Rahman A, Marimuthu S, Vishnu Kirthi A, Anbarasan $\mathrm{K}$, et al. (2017) Green synthesis of copper nanoparticles using Eclipta prostrate leaves extract and their antioxidant and cytotoxic activities. Experimental and therapeutic medicine 14(1): 18-24.

16. Aminuzzaman M, Kei LM, Liang WH (2017) Green synthesis of copper oxide $(\mathrm{CuO})$ nanoparticles using banana peel extract and their photocatalytic activities. In AIP Conference Proceedings, AIP Publishing, USA, 1828(1): 020016.

17. Naika HR, Lingaraju K, Manjunath K, Kumar D, Nagaraju G, et al. (2015) Green synthesis of $\mathrm{CuO}$ nanoparticles using Gloriosa superba L. extract and their antibacterial activity. Journal of Taibah University for Science 9(1): 7-12.

18. Susrutha V, Karthikeyan KV (2014) Microwave-mediated green synthesis of copper oxide $(\mathrm{CuO})$ nanoparticles and applications in environmental pollution controlling studies. International Journal of VLSI and embedded system 5: 819-824.

19. Suresh Y, Annapurna S, Singh AK, Bhikshamaiah G (2014) Green synthesis and characterization of tea decoction stabilized copper nanoparticles. Int J Innov Res Sci Eng Technol 3(4): 11265-11270.

20. Devi HS, Singh TD (2014) Synthesis of copper oxide nanoparticles by a novel method and its application in the degradation of methyl orange. Adv Electron Electr Eng 4(1): 83-88.

21. Asghar MA, Zahir E, Shahid SM, Khan MN, Asghar MA, et al. (2018) Iron, copper and silver nanoparticles: Green synthesis using green and black tea leaves extracts and evaluation of antibacterial, antifungal and aflatoxin B 1 adsorption activity. LWT 90: 98-107.

22. Graham Harold N (1992) Green tea composition, consumption, and polyphenol chemistry. Preventive medicine 21(3): 334-350.

23. Es' haghzade Z, Pajootan E, Bahrami H, Arami M (2017) Facile synthesis of $\mathrm{Fe} 304$ nanoparticles via aqueous based electrochemical route for heterogeneous electro-Fenton removal of azo dyes. Journal of the Taiwan Institute of Chemical Engineers 71: 91-105.

24. Shu HY, Chang MC, Tseng TH (2017) Solar and Visible Light Illumination on Immobilized Nano Zinc Oxide for the Degradation and Mineralization of Orange G in Wastewater. Catalysts 7(5): 164.

25. El-Kacemi S, Zazou H, Oturan N, Dietze M, Hamdani M, et al. (2017) Nanostructured $\mathrm{ZnO}_{-} \mathrm{TiO}_{2}$ thin film oxide as anode material in electrooxidation of organic pollutants. Application to the removal of dye Amido black 10B from water. Environmental Science and Pollution Research 24(2): 1442-1449.

26. Ghasemi E, Ziyadi H, Afshar AM, Sillanpää M (2015) Iron oxide nanofibers: A new magnetic catalyst for azo dyes degradation in aqueous solution. Chemical Engineering Journal 264: 146-151.

27. Malwal D, Gopinath P (2016) Enhanced photocatalytic activity of hierarchical three-dimensional metal oxide@CuO nanostructures towards the degradation of Congo red dye under solar radiation. Catalysis Science \& Technology 6(12): 4458-4472.

28. Nassar MY, Mohamed TY, Ahmed IS, Mohamed NM, Khatab M (2017) Hydrothermally synthesized $\mathrm{Co}_{3} \mathrm{O}_{4}, \alpha-\mathrm{Fe}_{2} \mathrm{O}_{3}$, and $\mathrm{CoFe}_{2} \mathrm{O}_{4}$ nanostructures: efficient nano-adsorbents for the removal of orange $\mathrm{G}$ textile dye from aqueous media. Journal of Inorganic and Organometallic Polymers and Materials 27(5): 1526-1537.

29. Dil EA, Ghaedi M, Asfaram A (2017) The performance of nanorods material as adsorbent for removal of azo dyes and heavy metal ions: application of ultrasound wave, optimization and modeling. Ultrasonics Sonochemistry 34: 792-802.

30. Shanthi M, Kuzhalosai V (2012) Photocatalytic degradation of an azo dye, Acid Red 27, in aqueous solution using nano ZnO. Indian Journal of Chemistry 51A: 428-434. 
31. Divya N, Bansal A, Jana AK (2013) Photocatalytic degradation of azo dye Orange II in aqueous solutions using copper-impregnated titania. International Journal of Environmental Science and Technology 10(6): 1265-1274.

32. Ghaedi M, Shojaeipour E, Ghaedi AM, Sahraei R (2015) Isotherm and kinetics study of malachite green adsorption onto copper nanowires loaded on activated carbon: Artificial neural network modeling and genetic algorithm optimization. Spectrochimica Acta Part A: Molecular and Biomolecular Spectroscopy, 142: 135-149.

33. Zhang P, Hou D, O'Connor D, Li X, Pehkonen SO, et al. (2018) Green and Size-Specific Synthesis of Stable Fe-Cu Oxides as Earth-Abundant Adsorbents for Malachite Green Removal. ACS Sustainable Chemistry \& Engineering 6 (7): 9229-9236.

\section{(C) \\ This work is licensed under Creative \\ Commons Attribution 4.0 License}

To Submit Your Article Click Here: Submit Article

DOI: $10.32474 /$ AOICS.2018.03.000174

\section{AOICS}

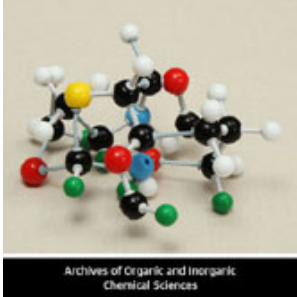

\section{Archives of Organic and Inorganic} Chemical Sciences

\section{Assets of Publishing with us}

- Global archiving of articles

- Immediate, unrestricted online access

- Rigorous Peer Review Process

- Authors Retain Copyrights

- Unique DOI for all articles 